\title{
Îndice general
}

Introducción -1

\section{Parte I: Cuestiones generales y estudios diacrónicos}

María Victoria Pavón Lucero

Relaciones entre oraciones y subordinación adverbial - 11

Cristina Matute y Teresa María Rodríguez Ramalle

Los adverbios y la estructura informativa en el margen preverbal de las oraciones subordinadas en español antiguo - 41

Rosa María Espinosa Elorza

Los cambios en las fronteras entre relativos, interrogativos y

conjunciones -101

Cristina Sánchez López

Cuando la gramaticalización se detiene: el caso de durante que y mediante que - 123

\section{Parte II: Estudios sincrónicos}

José María Brucart y Ángel J. Gallego

Aspectos formales e interpretativos de la subordinación adverbial -161

Antonio Fábregas

Cómo, cuándo y dónde donde, como y cuando se emplean como

preposiciones -201

Edita Gutiérrez Rodríguez y Pilar Pérez Ocón

Rasgos gramaticales de adverbios y pronombres relativos en construcciones existenciales -233

Mabel Giammatteo e Hilda Albano

De la periferia oracional a la estructura interna: las condicionales argumentales -281 
VI _ Índice general

Laura Brugè y Avel-lina Suñer

Las subordinadas temporales comparativas - 303 